\title{
Fractionation of Soil Inorganic Phosphate by a Modification of Chang and Jackson's Procedure ${ }^{1}$
}

\author{
J. D. H. Williams, J. K. Syers, and T. W. W Alker $^{2}$
}

\begin{abstract}
A modified version of the phosphate fractionation procedure of Chang and Jackson (1957) included the determination of "residual inorg. P' and introduced a revised nomenclature for the other fractions. Added phosphate sorbed during the fluoride extraction was usually completely recovered in the succeeding sodium hydroxide extraction; this enabled mutually compensating corrections to be applied to $\mathrm{NH}_{4} \mathrm{~F}-\mathrm{P}$ and 1 st $\mathrm{NaOH}-\mathrm{P}$ values. $A$ second acid treatment increased the amount of Ca-P extracted. Further modifications simplified the colorimetric determinations of inorganic phosphate in several of the extracts. A measure of the reproducibility of fractionation results was also obtained.
\end{abstract}

Additional Key Words for Indexing: revised nomenclature.

QINCE ITS INCEPTION the phosphate fractionation procedure $D$ of Chang and Jackson (1957) has been widely used for investigations into the forms of native phosphate and transformations of applied phosphate in soils. However, the procedure has been criticized in the light of subsequent findings concerning the effects of various extractants on pure compounds and on soils (Fife, 1959a, 1959b, 1962, 1963; Saunders, 1959; Khin and Leeper, 1960; Smith, 1965). A modified version $^{3}$ of the original scheme was used as the starting point in a further revision of the procedure.

\section{MATERIALS}

To date, the fractionation procedure has been tested on a range of New Zealand soils, including a sequence of basaltic soils varying widely in degree of weathering, a graywacke rock sequence also varying in degree of weathering, a precipitation sequence of graywacke soils, and a chronosequence of soils developed on windblown sand. The soils are all unfertilized and freely drained;

${ }^{1}$ Contribution from the Dep. of Soil Sci. Lincoln College, Univ, of Canterbury, New Zealand. Supported in part by scholarships to the first two authors from the Commonwealth Scholarship and Fellowship Plan. Received May 24, 1967. Approved July, 31, 1967.

${ }^{2}$ Formerly Graduate Student now Scientific Officer, Rothamsted Exp. Sta., Harpenden, Herts., England; formerly Research Fellow now Project Associate, Univ. of Wisconsin; and Professor of Soil Science, respectively. 
Table 1-Procedure for the fractionation of soil inorganic phosphate and the nomenclature used

\begin{tabular}{|c|c|c|}
\hline $\begin{array}{l}\text { Stage } \\
\text { no. }\end{array}$ & Treatment & Name of fraction \\
\hline $\begin{array}{l}1 \\
2\end{array}$ & $\begin{array}{l}0.5 M \mathrm{NH}_{4} \mathrm{Cl} \text { for } 30 \mathrm{~min} \\
0.5 \mathrm{M} \mathrm{NH} \text {, pH } 8.2 \text {, for } 24 \mathrm{hr} \text {, with } \\
\text { correction for resorption of phos- } \\
\text { phate from solution during extrac- }\end{array}$ & easily-soluble P \\
\hline $\begin{array}{l}3 \\
4\end{array}$ & $\begin{array}{l}0.1 N \mathrm{NaOH}+1 M \mathrm{NaCl} \text { for } 17 \mathrm{hr} \\
\text { extraction with dithionite-citrate- } \\
\text { bicarbonate }\end{array}$ & Ist $\mathrm{NaOH}-\mathrm{P}$ \\
\hline $\begin{array}{l}\mathbf{5} \\
6\end{array}$ & $\begin{array}{l}1 M \mathrm{NaOH} \text { for } 17 \mathrm{hr} \\
0.5 N \mathrm{HCl} \text { for } 1 \mathrm{hr} \text {, followed by } \\
1 N \mathrm{HCl} \text { for } 4 \mathrm{hr} \text { if } 1 \mathrm{st} \mathrm{HCl}-\mathrm{P} \\
>20 \mathrm{ppm} \\
\text { ignition at } 550 \mathrm{C} \text { for } 1 \mathrm{hr}\end{array}$ & $\begin{array}{l}\text { reductant-soluble } \\
2 \text { nd } \mathrm{NaOH}-\mathrm{P} \\
\text { 1 st } \mathrm{HCl}-\mathrm{P} \\
\text { 2nd } \mathrm{HCl}-\mathrm{P} \\
\text { sum }=\text { acid-extractable } \mathrm{Ca}-\mathrm{P}\end{array}$ \\
\hline 7 & $\begin{array}{l}\text { followed by } 1 \mathrm{~N} \mathrm{HCl} \text { for } 16 \mathrm{hr} \\
\mathrm{Na}_{2} \mathrm{CO}_{3} \text { fusion }\end{array}$ & $\begin{array}{l}\text { residual org. } \mathrm{P} \\
\text { residual inorg. } \mathrm{P}\end{array}$ \\
\hline
\end{tabular}

consequently, this paper does not discuss the difficulties encountered when vivianite and other secondary ferrous compounds or fertilizer residues such as di-calcium phosphate are present in the materials undergoing fractionation.

\section{METHODS}

The procedure finally adopted is outlined in Table 1. The revised scheme contains two stages, during which "residual org. $\mathrm{P}$ " is removed prior to the determination of "residual inorg. $\mathrm{P}$," that do not appear in the modified version. ${ }^{3}$ A more non-committal nomenclature was preferred, for reasons which will be discussed in subsequent publications.

Duplicate $0.5-\mathrm{g}$ or $1.0-\mathrm{g}$ unground $(<2 \mathrm{~mm})$ or $<250 \mu$ samples were used. The residues were washed once only with saturated $\mathrm{NaCl}$ solution between stages 1 and 6 and with distilled water after the determination of "acid-extractable Ca-P" and residual org. $P$. All extractions, except in stages 4 and 7 , were performed at $25 \pm 1 \mathrm{C}$.

Phosphate in the extracts was determined by the method of Dickman and Bray (1940) as modified by Fife (1959a) except in stages 4 and 7 .

\section{RESULTS AND DISCUSSION Determination of Easily-Soluble $\mathbf{P}$}

For most soils this fraction was negligible. However, the standard treatment with $\mathrm{NH}_{4} \mathrm{Cl}$ solution removed over 100 ppm $\mathrm{P}$ from the $\mathrm{F} / \mathrm{H}$ horizons of two very young soils. Eleven consecutive extractions with $\mathrm{NH}_{4} \mathrm{Cl}$ solution with extraction time totalling 133 hours, removed 460 and $350 \mathrm{ppm} \mathrm{P,} \mathrm{res-}$ pectively, from these two exceptional horizons.

Measurable amounts of easily-soluble P, not exceeding 10 ppm $\mathrm{P}$, were occasionally found in other samples. In these cases the fraction was included in the estimate of $\mathrm{NH}_{4} \mathrm{~F}-\mathrm{P}$.

\section{Determination of $\mathrm{NH}_{4} \mathrm{~F}-\mathrm{P}$}

The work of Fife $(1962,1963)$ suggests that a 1-hour extraction with $\mathrm{NH}_{4} \mathrm{~F}$ solution does not remove all aluminum. bound phosphate from soils, and that a 24 -hour extraction is preferable. The $\mathrm{pH}$ of the fluoride reagent was fixed at 8.2. Organic matter in $10-\mathrm{ml}$ aliquots of the extracts was precipitated by the addition of $20 \mathrm{ml}$ of $0.8 M_{3} \mathrm{H}_{3} \mathrm{BO}_{3} / 0.5 \mathrm{~N} \mathrm{HCl} \mathrm{solu-}$ tion, followed by centrifugation.

${ }^{3}$ R. C. Glenn, P. H. Hsu, M. L. Jackson, and R. B. Corey, 1959. Flow sheet for soil phosphorus fractionation. Agronomy Abstracts, p. 9.
The determination of $\mathrm{NH}_{4} \mathrm{~F}-\mathrm{P}$ is complicated by the fact that soil ferric compounds sorb a part of the phosphate which is solubilized from other soil compounds during the extraction (Khin and Leeper, 1960; Fife, 1962). To overcome this difficulty Smith (1965) suggested a method based on values for the recovery of phosphate added at different levels to the fluoride extractant. In the procedure being described, a second soil sample, also pretreated with $\mathrm{NH}_{4} \mathrm{Cl}$ solution, was extracted with $\mathrm{NH}_{4} \mathrm{~F}$ solution of $\mathrm{pH} 8.2$ and containing $1.25 \mu \mathrm{g} \mathrm{P} / \mathrm{ml}$. $\mathrm{NH}_{4} \mathrm{~F}-\mathrm{P}$ values were corrected on the basis of the recovery values for the added phosphate. This was calculated as follows: the proportion of added phosphate sorbed by the soil during extraction (denoted by $S_{\mathfrak{a}}$ ) was calculaterl from the phosphate levels of fluoride extracts, with and without added phosphate.

Therefore:

$$
\begin{aligned}
& \qquad 1-\frac{\text { difference in phosphate levels }(\mu \mathrm{g} / \mathrm{ml})}{1.25}=\mathrm{S}_{\mathrm{a}} \text {, } \\
& \text { and } \\
& \text { corrected } \mathrm{NH}_{4} \mathrm{~F}-\mathrm{P}=\text { uncorrected } \mathrm{NH}_{4} \mathrm{~F}-\mathrm{P} \times \frac{1}{1-\mathrm{S}_{\mathrm{a}}}
\end{aligned}
$$

If the relation between sorbed phosphate and phospbate in solution is non-linear, neither correction procedure is entirely adequate. ${ }^{4}$

In a series of phosphate fractionations on sixteen New Zealand hasaltic soil profiles ${ }^{4}$ the recovery of added phosphate ranged from $80-90 \%$ for weakly weathered soils to less than $40 \%$ in the subsoil horizons of strongly weathered soils.

\section{Determination of 1st NaOH-P}

To facilitate centrifugation $1.1 \mathrm{NaCl}$ was added to the $\mathrm{NaOH}$ reagent.

In the case of 25 soil horizons, samples which had been treated with fluoride reagent containing added phosph ate were also extracted with the $\mathrm{NaOH}$ reagent. In all but two cases the added phosphate sorbed during the fluoride extraction was recovered in the $\mathrm{NaOH}$ extract, so that the total recovery of added phosphate in the two extracts averaged $97 \pm 5 \%$. Consequently assuming that the native soil phosphate behaved in the same manner as the added phosphate:

$$
\begin{aligned}
& \text { corrected 1st } \mathrm{NaOH}-\mathrm{P}=\text { uncorrected 1st NaOH-P } \\
& \qquad-\left(\text { corrected } \mathrm{NH}_{4} \mathrm{~F}-\mathrm{P}-\text { uncorrected } \mathrm{NH}_{4} \mathrm{~F}-\mathrm{P}\right) .
\end{aligned}
$$

This correction, however, when applied to the two exceptional horizons, gave rise to negative values of 1 st $\mathrm{NaOH}-\mathrm{P}$, and it was found that the $\mathrm{NaOH}$ extraction recovered about a half only of the added phosphate which had been sorbed during the fluoride extraction. When a correction that allowed for the incomplete recovery was applied, low, but positive, values of 1st NaOH-P were obtained for these horizons. Increasing the strength of the $\mathrm{NaOH}$ extractant to $1 M$ might overcome the problem of incomplete recovery.

In sixteen profiles of basaltic soils ${ }^{4}$ the ratio of uncorrected $\mathrm{NH}_{4} \mathrm{~F}-\mathrm{P}$ to uncorrected 1st NaOH-P exceeded unity in only two cases. The number of cases increased to eight, however,

${ }^{4} \mathrm{~J}$. D. H. Williams, 1965. Forms of soil phosphate in some genetically-related New Zealand soils. Ph.D. Thesis. Lincoln College, University of Canterbury, New Zealand. 
Table 2-Mean values of uncorrected and corrected $\mathrm{NH}_{4} \mathrm{~F}-\mathrm{P}$ and 1st NaOH.P for 16 New Zealand basaltic soil profilesO

\begin{tabular}{|c|c|c|c|c|c|c|}
\hline Soil & $\begin{array}{c}\text { Uncorr. } \\
\underset{\text { (a) }}{\mathrm{NH}_{4} \mathrm{~F}-\mathrm{P}}\end{array}$ & $\begin{array}{l}\text { Corr. } \\
\text { NHif-P }\end{array}$ & $\begin{array}{l}\text { Uncorr } \\
\text { 1st } \underset{\text { NaOH-P }}{\text { (c) }}\end{array}$ & 1st $\underset{\text { (d) }}{\mathrm{NaOH}}$ & $a / c$ & $b / d$ \\
\hline Camphill & 17 & 22 & ${ }_{42}$ & 37 & 0.40 & 050 \\
\hline Evans & 130 & $\begin{array}{r}22 \\
150\end{array}$ & $\begin{array}{r}42 \\
151\end{array}$ & 131 & $\begin{array}{l}0.40 \\
0.86\end{array}$ & 0.59 \\
\hline Highcliff & 60 & 75 & 88 & 73 & 0.68 & 1.03 \\
\hline Stewart & 684 & 900 & 681 & 464 & 1.00 & 1.94 \\
\hline Dasher & 244 & 428 & 430 & 246 & 0.57 & 1.74 \\
\hline Miri & 24 & 43 & 70 & 51 & 0.34 & 0.84 \\
\hline Waiareks & 93 & 114 & 112 & 91 & 0.83 & 1.25 \\
\hline Ohaeawai & 93 & 151 & 69 & 26 & 1.35 & 5.81 \\
\hline Papakauri & 19 & 34 & 84 & 69 & 0.23 & 0.49 \\
\hline Kiripaka & 90 & 157 & 211 & 144 & 0.43 & 1.09 \\
\hline Maunu & 173 & 304 & 329 & 198 & 0.53 & 1.54 \\
\hline Apotu & 16 & 28 & 51 & 39 & 0.31 & 0.72 \\
\hline Waiotu & 31 & 78 & 175 & 128 & 0.18 & 0.61 \\
\hline Ruatangata & $1 \mathrm{I}$ & 17 & 36 & 30 & 0.31 & 0.57 \\
\hline Atawhai & 4 & 5 & 21 & 20 & 0.19 & 0.25 \\
\hline Okaihau & 2 & 3 & 61 & 60 & 0.03 & 0.05 \\
\hline
\end{tabular}

- Calculated using the volume-weight values of individual horizons.

Table 3-Proportion of added phosphate recovered in three stages of the fractionation procedure for individual horizons of several New Zealand basaltic soil profiles

\begin{tabular}{|c|c|c|c|c|c|c|}
\hline$\underset{\text { horizor }}{\text { Soil }+}$ & & $\mathrm{NH}_{4} \mathrm{~F}$ & $\mathrm{NaOH}$ & $\begin{array}{c}\mathrm{NH}_{4} \mathrm{~F} \\
+ \\
\mathrm{NaOH}^{+} \mathrm{H}\end{array}$ & $\begin{array}{c}\text { Dithionite- } \\
\text { citrate- } \\
\text { bicarbonate }\end{array}$ & $\begin{array}{c}\mathrm{NH}_{4} \mathrm{~F}+ \\
\mathrm{NaOH}+ \\
\text { dithionite- } \\
\text { citrate } \\
\text { bicarbonate }\end{array}$ \\
\hline Stewart & $\begin{array}{l}1 \\
2 \\
3\end{array}$ & $\begin{array}{l}0.82 \\
0.74 \\
0.75\end{array}$ & $\begin{array}{l}0.19 \\
0.35 \\
0.27\end{array}$ & $\begin{array}{l}1.01 \\
1.09 \\
1.02\end{array}$ & & \\
\hline Dasher & $\begin{array}{l}2 \\
3 \\
4\end{array}$ & $\begin{array}{l}0.26 \\
0.53 \\
0.71\end{array}$ & $\begin{array}{l}0.74 \\
0.43 \\
0.34\end{array}$ & $\begin{array}{l}1.00 \\
1.06 \\
1.05\end{array}$ & & \\
\hline Ohaenwai & 3 & 0.51 & 0.30 & 0.81 & 0.11 & 0.92 \\
\hline Okaihau & $\begin{array}{l}4 \\
1 \\
2 \\
4\end{array}$ & $\begin{array}{l}0.47 \\
0.58 \\
0.43 \\
0.46\end{array}$ & $\begin{array}{l}0.31 \\
0.40 \\
0.52 \\
0.47\end{array}$ & $\begin{array}{l}0.78 \\
0.98 \\
0.95 \\
0.93\end{array}$ & $\begin{array}{l}0.19 \\
0.03 \\
0.02 \\
0.03\end{array}$ & $\begin{array}{l}0.97 \\
1.01 \\
0.97 \\
0.96\end{array}$ \\
\hline
\end{tabular}

if corrected values were compared (Table 2). The same ratios for the 62 individual horizons of the profiles exceeded unity in 8 and 37 cases, respectively. The proportion of added phosphate recovered in three stages of the fractionation procedure for individual horizons of several basaltic soil profiles is shown in Table 3.

In two samples of beach sands containing $0.7 \%$ and $2.4 \%$ $\mathrm{CaCO}_{3}$ in the form of shells, $14.1 \%$ and $15.2 \%$, respectively, of phosphate added with the fluoride reagent was recovered in the acid-extractable $\mathrm{Ca}-\mathrm{P}$ fraction. This behavior reflects the ability of $\mathrm{CaCO}_{3}$ to sorb and retain phosphate against extraction by neutral or alkaline reagents. A $0.5-\mathrm{g}$ sample of "Analar" $\mathrm{CaCO}$. sorbed over $98 \%$ of the phosphate present in $100 \mathrm{ml}$ of $0.1 \mathrm{~N} \mathrm{NaOH}$ containing $5 \mu \mathrm{g} \mathrm{P} / \mathrm{ml}$. Consequently, the procedure, if applied to caicareous soils, may underestimate the $\mathrm{NH}_{4} \mathrm{~F}-\mathrm{P}$, 1st $\mathrm{NaOH}-\mathrm{P}$, reductant-soluble $\mathrm{P}$ and 2nd $\mathrm{NaOH}-\mathrm{P}$ fractions, and overestimate acid-extractable Ca-P by a compensating amount.

\section{Determination of Reductant-Soluble $\mathbf{P}$}

The dithionite-citrate-bicarbonate reagent of Mehra and Jackson (1960) has the advantage of being buffered against decrease in $\mathrm{pH}$ during reaction with the soil; consequently, dissolution of apatite is minimized. The effectiveness of the reagent in this respect was shown by the fractionation results for a sample of unweathered finely ground mica-schist, which

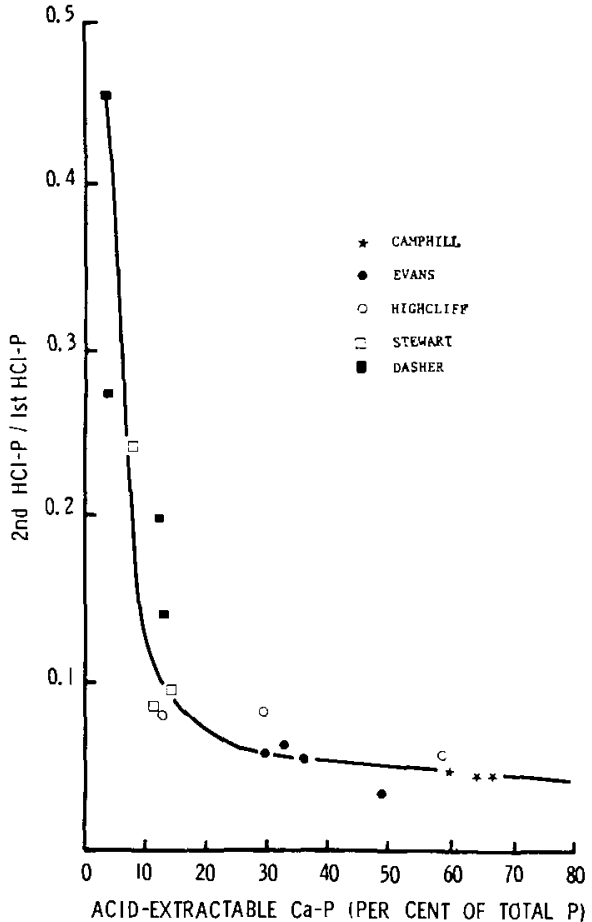

Fig. 1-2nd HCl-P/1st HCl-P and acid-extractable Ca-P for the horizons of five weakly weathered New Zealand soil profiles.

contained $750 \mathrm{ppm}$ acid-extractable $\mathrm{Ca}-\mathrm{P}$ but only $6 \mathrm{ppm}$ reductant-soluble $P$.

The inorganic phosphate content of the extracts was determined by the method of Watanabe and Olsen (1962), after oxidation of dithionite by allowing the flasks to stand exposed to the atmosphere.

\section{Determination of 2nd $\mathrm{NaOH}-\mathrm{P}$}

Because of difficulties associated with the determination of residual org. $\mathrm{P}$ (see below) the strength of the $\mathrm{NaOH}$ extractant was increased to $1 M$ and the extraction time increased to 17 hours.

\section{Determination of Acid-Extractable Ca-P}

In the determination of this fraction $\mathrm{HCl}$ was substituted for $\mathrm{H}_{2} \mathrm{SO}_{4}$. As a result, phosphate in the extract was determined by the colorimetric procedure of Dickman and Bray (1940), which tolerates ferric iron better than sulfomolybdic acid procedures (Jackson, 1958, p. 145) and which moreover was used for determining most of the other fractions.

Although a 1-hour extraction with $0.5 \mathrm{~N}$ acid will completely dissolve samples of pure apatite (Chang and Jackson, 1957) it was found that a second extraction with acid removed additional amounts of phosphate from soils high in 1st HCl-P. The ratio of the quantities of phosphate in the first and second extracts was closely related to their sum when expressed as a percentage of total $P$ (Fig. 1) suggesting that the phosphate in both $\mathrm{HCl}$ extracts originated from apatite. The presence of apatite inclusions within primary minerals in some of the samples is probably responsible for the discrepancy between these findings and those of Chang and Jack- 
Table 4-Reproducibility of phosphate fractionation results for one sample included in each of fre different batches

\begin{tabular}{|c|c|c|c|c|c|c|c|c|}
\hline Batch no. & $\mathrm{NH}_{4} \mathrm{~F}-\mathrm{P}$ & $\stackrel{\text { lst }}{\mathrm{NaOH}-\mathrm{P}}$ & $\begin{array}{l}\text { Reductant- } \\
\text { soluble P }\end{array}$ & $\underset{\mathrm{NaOH}-\mathrm{P}}{2 \text { nd }}$ & $\begin{array}{l}\text { Acid- } \\
\text { extractable Ca-P }\end{array}$ & $\begin{array}{l}\text { Residual } \\
\text { inorg. } P\end{array}$ & $\begin{array}{l}\text { Total } \\
\text { inorg. } \mathrm{P}\end{array}$ & $\begin{array}{l}\text { Residual } \\
\text { arg. } \mathbf{P}\end{array}$ \\
\hline $\begin{array}{c}1 \\
2 \\
3 \\
4 \\
5 \\
\text { Mean }\end{array}$ & $\begin{array}{l}340 \\
375 \\
379 \\
382 \\
339 \\
363 \\
\pm 22\end{array}$ & $\begin{array}{c}192 \\
166 \\
204 \\
199 \\
198 \\
192 \\
\pm 15\end{array}$ & $\begin{array}{r}493 \\
466 \\
466 \\
496 \\
464 \\
477 \\
\pm 16\end{array}$ & $\begin{array}{l}143 \\
141 \\
132 \\
146 \\
132 \\
130 \\
\pm 6\end{array}$ & $\begin{array}{r}0 \\
3 \\
3 \\
3 \\
0 \\
2 \\
+2\end{array}$ & $\begin{array}{c}70 \\
62 \\
64 \\
68 \\
78 \\
68 \\
\pm 6\end{array}$ & $\begin{array}{l}1238 \\
1213 \\
1248 \\
1294 \\
1211 \\
1241 \\
\pm 37\end{array}$ & $\begin{array}{l}38 \\
52 \\
42 \\
53 \\
53 \\
48 \\
\pm 7\end{array}$ \\
\hline
\end{tabular}

- Sum of inorganic P fractions.

son (1957). For this reason the sum of 1st HCl-P and 2nd HCl-P was denoted by the expression acid-extractable Ca-P.

Fractionation of a sample of unweathered mica-schist containing $790 \mathrm{ppm}$ total $P$ gave a value of $750 \mathrm{ppm}$ for the acidextractable $\mathrm{Ca}-\mathrm{P}$ fraction while several moderately or strongly weathered basaltic soils apparently contained no acid-extractable Ca-P. These results agree with the postulated behavior of apatite during soil weathering (Chang and Jackson, 1958), suggesting that during fractionation no appreciable dissolution of apatite occurs prior to the determination of acid-extractable Ca-P and also that this fraction, as determined in this procedure, does not contain any aluminum- or iron-bound phosphate.

\section{Determination of Residual Org. P}

The determination of a fraction corresponding to acid-extractable Ca-P constitutes the last stage in the initial modification ${ }^{3}$ of the Chang and Jackson "procedure. However, it was found that the procedure, if terminated at this point, did not extract all the phosphate present in any of the samples investigated. Khin and Leeper (1960) also found appreciable amounts of "residual" phosphate in a Krasnozem soil horizon.

In an attempt to distinguish between organic and inorganic forms of residual phosphate, residual org. $P$ was removed and determined by a procedure based on the "ignition" method for total organic P of Walker and Adams (1958). In an attempt to minimize systematic errors associated with organic phosphate determination by ignition methods (Anderson, 1960; Williams and Walker, submitted for publication), as much phosphate as possible was removed from the sample prior to the determination of residual org. $\mathrm{P}$, and it was for this reason that the severity of the second $\mathrm{NaOH}$ extraction was increased (see above). Regression analysis of the residual org. $P$ and total organic $P$ values for 16 basaltic soil profiles, both sets of values being expressed as a percentage of the total phosphate in the profile, gave a correlation coefficient of $0.73^{* *}(0.01)$, supporting the view that the residual org. $\mathrm{P}$ fraction of these soils was largely composed of organic phosphate.

\section{Determination of Residual Inorg. $\mathbf{P}$}

This fraction was initially determined by HF digestion of the residue, but was subsequently determined by $\mathrm{Na}_{2} \mathrm{CO}_{3}$ fusion (Muir, 1952) [except that $9 \mathrm{~N} \mathrm{H}_{2} \mathrm{SO}_{4}$ was used for removal of the melt (Jackson, 1958)] after it was found that the fusion procedure gave higher values in some instances, Phosphate was determined colorimetrically by the method of Fogg and Wilkinson (1958). In some of the soils examined this fraction consisted largely of included apatite not removed by the $\mathrm{HCl}$ treatments because of positional nonextractability. The significance of apatite inclusions in soil phosphorus studies will be discussed in a future publication.

To test the reproducibility of fractionation results, one sample was included in each of five different batches of samples undergoing fractionation. The results (Table 4) suggest that random errors as high as $20-30 \mathrm{ppm}$ are possible in the determination of individual fractions, and random errors of $3 \%$ or more in the determination of "total inorg. P."

\section{LITERATURE CITED}

1. Anderson, G. 1960. Factors affecting the estimation of phosphate esters in soil. J. Sci. Food Agr. 11:497-503.

2. Chang, S. C., and M. L. Jackson. 1957. Fractionation of soil phosphorus. Soil Sci. 84:133-144.

3. Chang, S. C., and M. L. Jackson. 1958. Soil phosphorus fractions in some representative soils. J. Soil Sci. 9:109-119.

4. Dickman, S. R., and R. H. Bray. 1940. Colorimetric determination of phosphate. Ind. Eng. Chem. Anal. Ed. $12: 665-668$.

5. Fife, C. V. 1959a, 1959b, 1962, 1963. An evaluation of ammonium fluoride as a selective extractant for aluminumbound soil phosphate: I-IV. Soil Sci. 87:13-21, 83-88; $93: 113-123 ; 96: 112-120$.

6. Fogg, D. N., and N. T. Wilkinson. 1958. The colorimetric determination of phosphorus. Analyst 83:406-414.

7. Jackson, M. L. 1958. Soil chemical analysis. PrenticeHall, Inc., Englewood Cliffs, N. J.

8. Khin, A., and G. W. Leeper. 1960. Modifications in Chang and Jackson's procedure for fractionating soil phosphorus. Agrochimica 4:246-254.

9. Mehra, O. P., and M. L. Jackson. 1960. Iron oxide removal from soils and clays by a dithionite-citrate system buffered with sodium bicarbonate. Proc. 7th Nat. Conf. Clays, 1959, 5:317-327.

10. Muir, J. W. 1952. The determination of total phosphorus in soil, with particular reference to the control of interference by soluble silica. Analyst 77:313-317.

11. Saunders, W. M. H. 1959. Aluminum extracted by neutral citrate-dithionite reagent. Nature 184:2037.

12. Smith, A. N. 1965. Distinction between iron and aluminum phosphate in Chang and Jackson's procedure for fractionating inorganic soil phosphorus. Agrochimica 9:162-168.

13. Walker, T. W., and A. F. R. Adams. 1958. Studies on soil organic matter: 1. Influence of phosphorus content of parent materials on accumulations of carbon, nitrogen, sulphur, and organic phosphorus in grassland soils. Soil Sci. 85:307-318.

14. Watanabe, F. S., and S. R. Olsen. 1962. "Colorimetrie determination of phosphorus in water extracts of soil. Soil. Sci. 93:183-188. 